\title{
Effect of Steel-refractory Reactions on Removal of Arsenic from Molten Steel with Lanthanum Additions
}

\author{
Hongpo WANG, ${ }^{1) *}$ Silu JIANG, ${ }^{1)}$ Peng YU, ${ }^{1)}$ Lifeng SUN ${ }^{21}$ and Yu WANG ${ }^{1)}$ \\ 1) College of Materials Science and Engineering, Chongqing University, Chongqing, 400044 China. \\ 2) Key Laboratory for Ecological Metallurgy of Multimetallic Mineral (Ministry of Education), Northeastern University, \\ Shenyang, 110819 China.
}

(Received on January 28, 2020; accepted on May 25, 2020; J-STAGE Advance published date: June 29, 2020)

\begin{abstract}
To formulate strategies to remove arsenic from molten steel by adding rare earth elements (REs), the evolution of inclusions in steel with different lanthanum additions was studied, and the effect of reactions between lanthanum and magnesium crucibles on the removal of arsenic was discussed. The results show that the addition of lanthanum can remove arsenic from molten steel, but steel-refractory reactions dramatically influenced the removal effect. The arsenic removal was determined by the generation of La-SAs. The reactions between lanthanum and magnesia crucibles partly consumed lanthanum and decreased its effective concentration acting on arsenic. Further, the reaction product dissolved magnesium consumed a part of sulfur that was disadvantageous for the formation of La-S-As. Besides, a sequence of reactions existed after the addition of lanthanum. The original Si-Mn-Al-O inclusions were changed to lanthanumcontaining oxides first and then to $\mathrm{MgO}$-rich oxides. The reaction to generate La-S-As mainly took place within $5 \mathrm{~min}$. The consumption of REs by crucible refractories is an important issue that needs consideration. Alumina crucibles are more favored over magnesia crucibles when using REs to remove arsenic from molten steel.
\end{abstract}

KEY WORDS: rare earth; inclusion; arsenic; refractory; evolution.

\section{Introduction}

Low-melting trace elements such as arsenic, tin, and copper, have always been one of the critical factors that endanger the quality and performance of steel products. These elements are easy to segregate at phase- and grainboundaries and significantly reduce the binding force of the interfaces, detrimental to the mechanical properties. ${ }^{1-3)}$ Temper embrittlement is one of the common hazards caused by trace elements. ${ }^{4)}$ The sources of arsenic in steel are mainly arsenic-containing iron ore and scrap steel. China has plenty of arsenic-containing iron ore, some of which are associated with antimony and lead. The arsenic content in steel will be high when using these arsenic-containing iron ore as raw materials. Furthermore, based on the demand for energy saving and pollution reduction, usage of scrap steel has increased year by year. Reutilization of scrap steel has caused the enrichment of arsenic, tin, copper, etc. It is incredibly harmful when multiple trace elements exist simultaneously. ${ }^{5-7)}$ Unfortunately, the current mainstream

\footnotetext{
* Corresponding author: E-mail: wanghp@cqu.edu.cn
}

steelmaking process cannot remove these trace elements since they have weak reactivity with oxygen.

Because of the strong chemical activity, rare earth elements (REs) have been tried to remove arsenic from molten steel and change its occurrence form in steel, which are potential methods to avoid or mitigate the harm of arsenic. Lanthanum and cerium, rich in reserves and relatively cheap, have been widely used in the iron and steel industry. ${ }^{8-12)}$ Baogang Group alone in China produces nearly ten million tons of RE-containing steel annually. The method by using REs to react with arsenic to generate inclusions can remove a part of arsenic; it generally requires a high addition amount of REs though. ${ }^{13,14)}$ REs can also react with the residual arsenic during the solidification and cooling process, resulting in a series of arsenic RE inclusions. ${ }^{15,16)}$ Thereby, the occurrence state of arsenic in steel has been improved, and the segregation of arsenic at grain boundaries has been weakened. ${ }^{3,17)}$ For arsenic RE inclusions, $\mathrm{LaAsO}_{4}$ and $\mathrm{CeAs}$ have been identified, but $\mathrm{La}-\mathrm{S}-\mathrm{As}, \mathrm{La}-\mathrm{As}$, etc. have not been identified yet. ${ }^{3,16,17)}$

The reactions between REs and refractories must be considered in the steelmaking process of RE-containing steels. Due to the strong chemical activity, except for reacting with 
Si-Mn-Al-O inclusions that already present in steel, ${ }^{18-20)}$ REs can also react with refractories made of alumina, magnesia, and spinels. ${ }^{21-23)}$ These reactions will reduce the effective concentration of REs. Even worse, the RErefractory reaction products can seriously affect the stability of continuous casting. RE-induced clogging of submerged nozzles is a problem frequently encountered in industrial production. ${ }^{24)}$ After the REs are dissolved in molten steel, the composition of original inclusions will be significantly changed. Some types of inclusions, such as $\mathrm{REAlO}_{3}$, will be enriched on the surface of submerged nozzles, leading to a reduction of their inner diameter; whereas, REs will significantly erode silica refractories and increase the inner diameter of submerged nozzles. ${ }^{25)}$

During the steelmaking process in the laboratory, alumina and magnesia crucibles have been widely used. When preparing RE-containing steels, the reactions between REs and crucibles directly affect the effective amount of REs, which significantly affects the expected experimental results. The purpose of this study is to investigate the effect of adding lanthanum on the arsenic removal from molten steel when preparing arsenic-containing steels in magnesia crucibles, and the influence of steel-refractory reactions on the evolution of inclusions has also been discussed.

\section{Materials and Methods}

We used industrial high carbon steel billets as raw materials. Before steelmaking, we forged them into round rods to uniformize the chemical composition, and the crosssectional size changed from $150 \mathrm{~mm} \times 150 \mathrm{~mm}$ to $65 \mathrm{~mm}$ in diameter. Chemical compositions of the obtained round rods are shown in Table $\mathbf{1 .}$

The steelmaking process was carried out using a $15 \mathrm{~kW}$ induction furnace under the protection of argon gas with a purity of 99.999 mass \%. The initial mass of the raw materials was about $550 \mathrm{~g}$ for each experiment. After being polished, the raw materials were put into magnesia crucibles and placed in the induction furnace. After evacuating, argon gas was filled in. This process was performed twice before the start of heating. The flow rate of argon gas was set to $0.8 \mathrm{~L} / \mathrm{min}$ for $10 \mathrm{~min}$ and adjusted to $0.3 \mathrm{~L} / \mathrm{min}$. Then the heating process has been carried out by gradually increasing the output voltage of the induction furnace. It took around $50 \mathrm{~min}$ to reach $1600^{\circ} \mathrm{C}$. After the raw materials were melted for $10 \mathrm{~min}$, arsenic particles with a purity of 99.9\% were added. High-purity iron sheets were used to wrap arsenic particles, together with about $5 \mathrm{~g}$ steel rods. We put them in a quartz tube with one head closed and used magnets to hold them. When the magnets were removed, arsenic particles were added and sunk into molten steel. After another $10 \mathrm{~min}$, lanthanum particles were added in the same way. Then, six samples in total were taken from molten steel every 5 min. Quartz tubes with an inner diameter of $4 \mathrm{~mm}$ were used to extract molten steel, followed by water-quenching. The process from sample extraction to water-quenching was about 3 seconds. The induction furnace power was turned off after $20 \mathrm{~min}$ of the lanthanum addition, and the steel ingots were cooled to room temperature in the furnace. The initial additions of arsenic were set to $0.020 \%(0.025 \%$ in content $)$, and the initial lanthanum
Table 1. Chemical compositions of the obtained rods (mass $\%$ ).

\begin{tabular}{ccccccccc}
\hline Elements & $\mathrm{C}$ & $\mathrm{Si}$ & $\mathrm{Mn}$ & $\mathrm{P}$ & $\mathrm{S}$ & $\mathrm{Al}$ & $\mathrm{O}$ & $\mathrm{As}$ \\
\hline Concentrations & 0.79 & 0.21 & 0.61 & 0.011 & 0.015 & 0.001 & 0.0024 & 0.005 \\
\hline
\end{tabular}

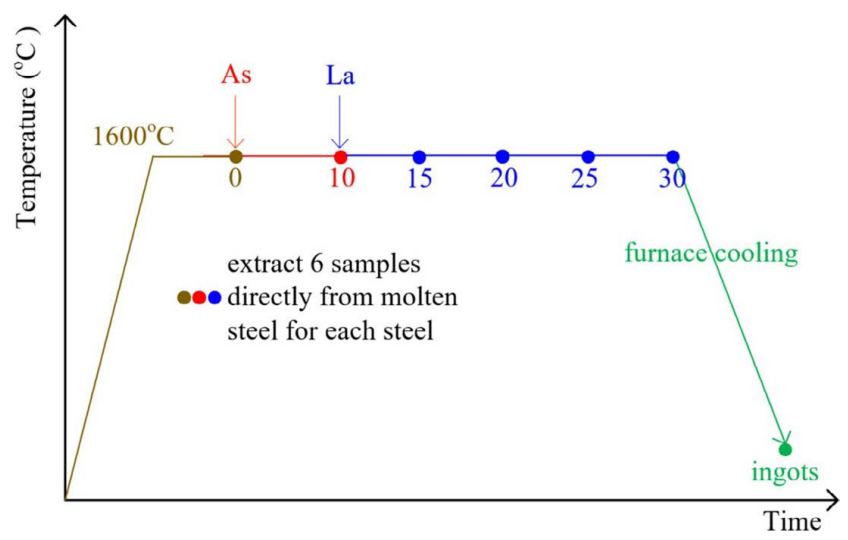

Fig. 1. Details of steelmaking and sampling process. (Online version in color.)

additions were set to $0.15 \%, 0.10 \%$, and $0.05 \%$, respectively. Figure 1 shows the process of sample preparation.

Samples were also taken at the $1 / 2$ height and $1 / 2$ radius of steel ingots for the measurement of chemical compositions. The content of lanthanum, arsenic, magnesium, and acid-soluble aluminum were measured with an inductively coupled plasma optical emission spectrometer (Optima 8000, Waltham, MA, USA). Inclusions were observed with an optical microscope (OM, Sunny XD30M, Ningbo, Zhejiang, China) and a scanning electron microscope (SEM, JEOL 7800F, Tokyo, Japan). Besides, the compositions of inclusions were identified with an energy dispersive spectrometer (EDS, $80 \mathrm{~mm}^{2} \mathrm{X}-\mathrm{Max}^{\mathrm{N}}$ Silicon Drift Detector, Oxford, UK). For the water-quenched samples, no less than 50 inclusions were randomly chosen to analyze their chemical compositions for each sample.

\section{Results and Discussion}

\subsection{Evolution of Inclusions in Molten Steel}

Inclusions in molten steel turned out to be mainly $\mathrm{Si}-\mathrm{Mn}-$ Al-O before the addition of lanthanum, as shown in Fig. 2. The evolution of inclusions involves $\mathrm{Si}-\mathrm{Mn}-\mathrm{Al}-\mathrm{La}-\mathrm{Mg}-\mathrm{O}$ after lanthanum was added, as shown in Fig. 3. To conveniently describe the evolution, we plot ternary phase diagrams with $\mathrm{MgO}, \mathrm{La}_{2} \mathrm{O}_{3}$, and $\mathrm{Si}-\mathrm{Mn}-\mathrm{Al}-\mathrm{O}$ as components. Three factors determined the compositions of the $\mathrm{Si}-\mathrm{Mn}-$ $\mathrm{Al}-\mathrm{La}-\mathrm{Mg}-\mathrm{O}$ inclusions: the $\mathrm{Si}-\mathrm{Mn}-\mathrm{Al}-\mathrm{O}$ oxides initially present in molten steel, the modification of lanthanum, and the magnesium derived from the reaction of lanthanum with the crucible. The ability of [Si] and [Mn] to react with [O] is much weaker than that of [La], $[\mathrm{Al}]$, and $[\mathrm{Mg}]$, and the competition for reacting with [O] mainly comes from the latter three. Therefore, we regard $\mathrm{Si}-\mathrm{Mn}-\mathrm{Al}-\mathrm{O}$ as one component to conveniently describe the evolution of inclusions. And the $0.15 \%$ La-added steel was chosen here since it had the most significant evolution process.

The results show that the addition of lanthanum significantly changed the compositions of inclusions. Almost 
all inclusions changed from (Mg-La)-free to (Mg-La)containing ones after adding lanthanum for $5 \mathrm{~min}$, owing to the strong reactivity among lanthanum, magnesium, and oxygen. It is inferred that the magnesium was derived from

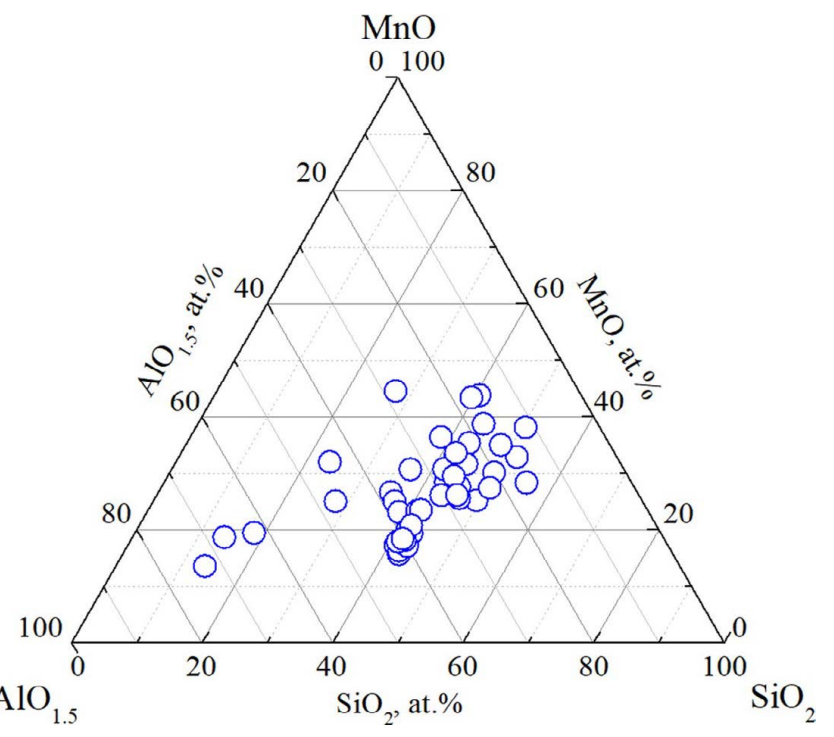

Fig. 2. Compositions of inclusions in the La-free molten steel. (Online version in color.)

(a)
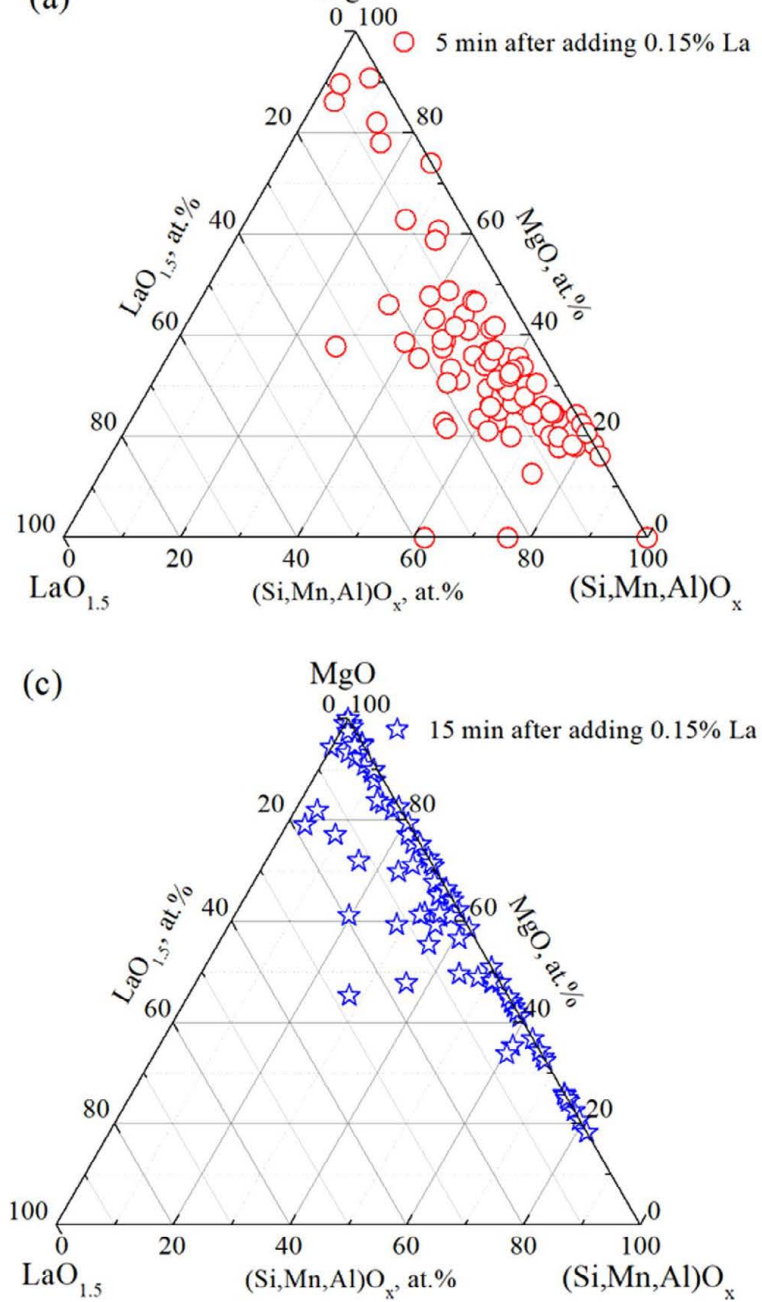

the reactions between lanthanum and the magnesia crucible because no other sources of magnesium existed here. With the extension of the isothermal time, the amount of Lacontaining inclusions gradually decreased, and the amount of Mg-containing inclusions increased.

After 20 min of adding lanthanum, the amount of Lacontaining inclusions became few, and the inclusions were finally changed to mostly $\mathrm{MgO}$. This is consistent with the evolution of inclusions when smelting La-containing steels using alumina crucibles. This is to say, the addition of lanthanum will change the existing $\mathrm{Si}-\mathrm{Mn}-\mathrm{Al}-\mathrm{O}$ inclusions to La-containing oxides first, and then to $\mathrm{Al}_{2} \mathrm{O}_{3}$-rich (using alumina crucibles) or $\mathrm{MgO}$-rich (using magnesia crucibles) composite oxides. ${ }^{26)}$ The evolution mechanism will be discussed in section 3.4.

Except for the $\mathrm{Si}-\mathrm{Mn}-\mathrm{Al}-\mathrm{La}-\mathrm{Mg}-\mathrm{O}$ inclusions, a few La-As inclusions with a size around several hundred nanometers were also found in water-quenched samples. They possibly precipitated during solidification even the consumed time before quenching was only around 3 seconds. ${ }^{17)}$ We do not make a detailed discussion about them here.

\subsection{Changes in Chemical Compositions of Steel in the Whole Steelmaking Process}

The addition of lanthanum significantly changed the com-
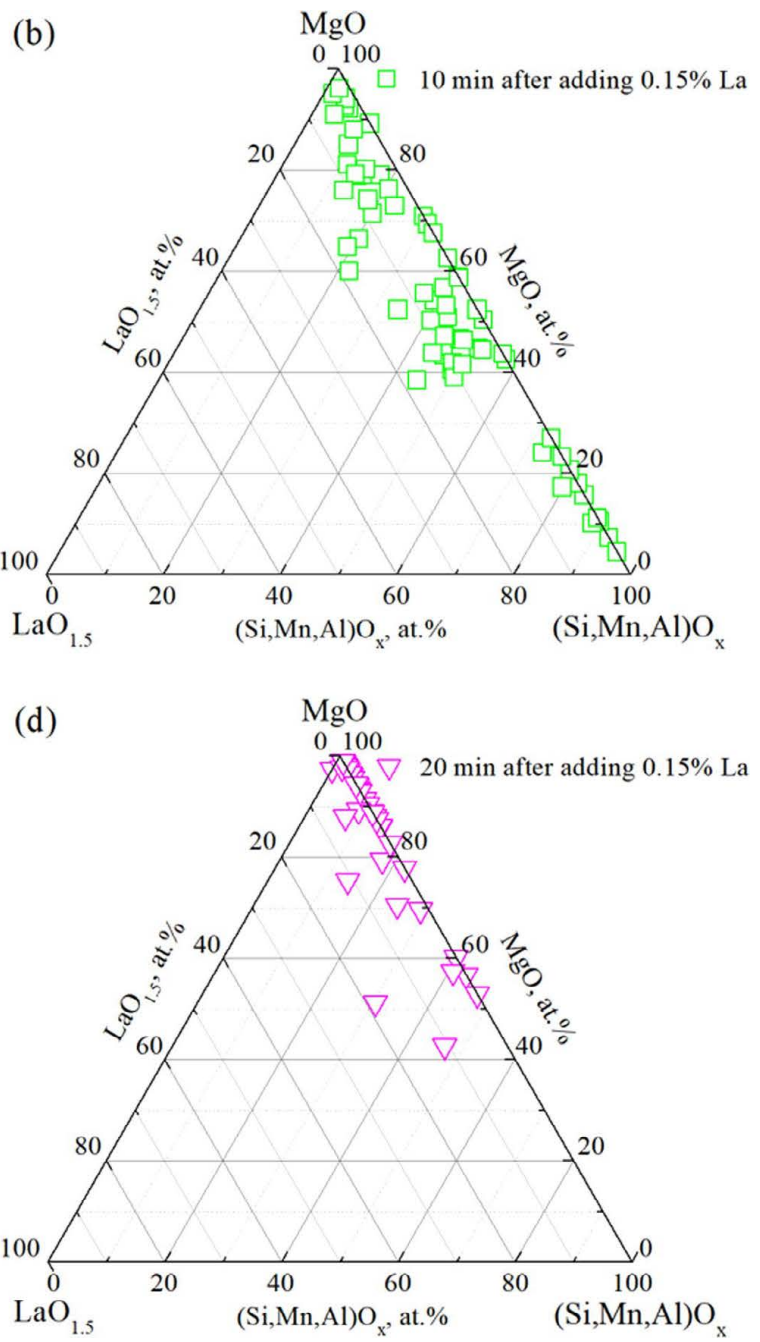

Fig. 3. Evolution of inclusions in molten steel with the increasing isothermal time. (a) to (d) after adding $0.15 \%$ La for $5 \mathrm{~min}, 10 \mathrm{~min}, 15 \mathrm{~min}$, and $20 \mathrm{~min}$, respectively. (Online version in color.) 

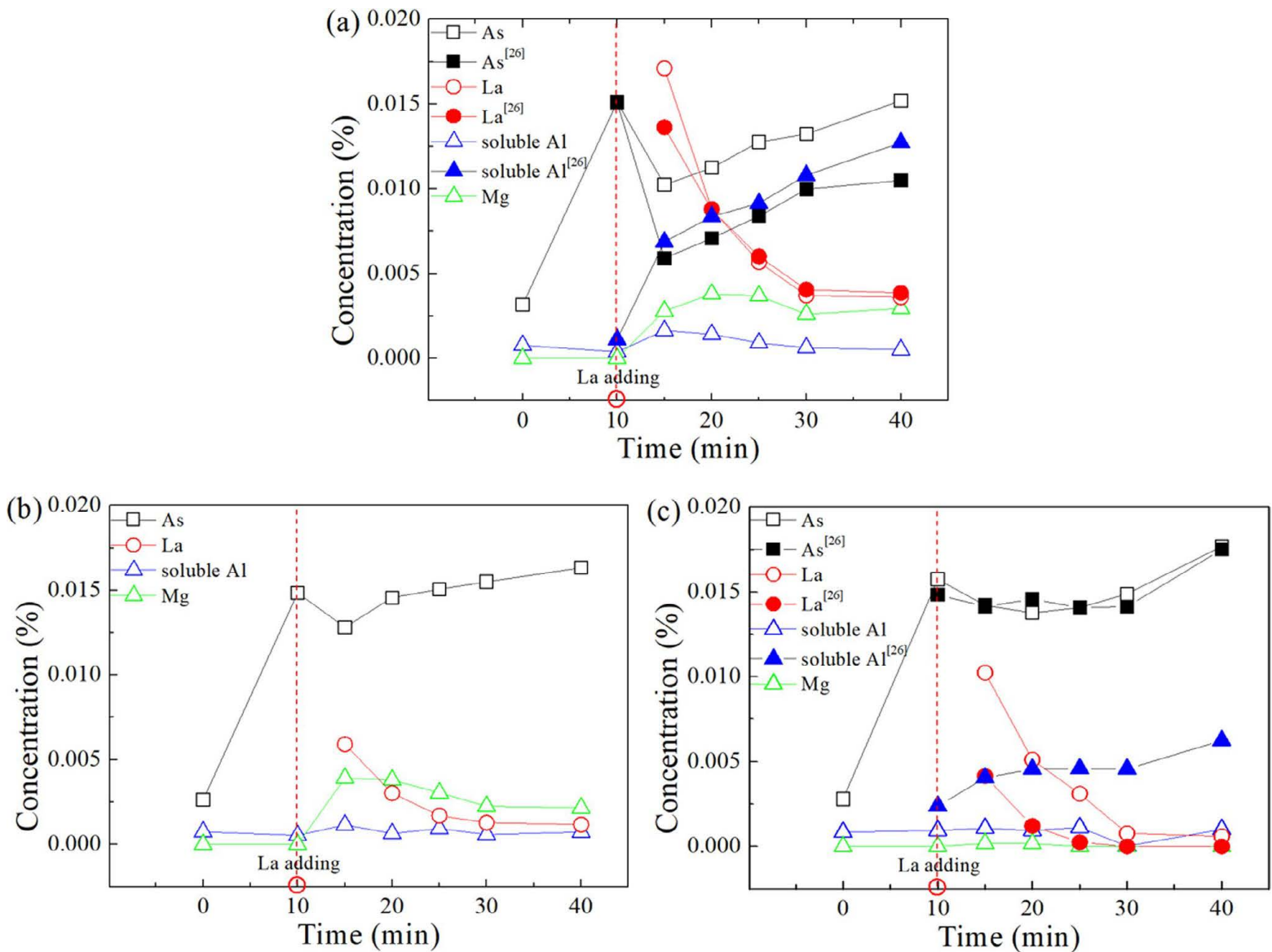

Fig. 4. Changes in concentrations of arsenic, acid-soluble aluminum, magnesium, and lanthanum in steel during the whole steelmaking process (Arsenic additions were made at $0 \mathrm{~min}$ and lanthanum additions at $10 \mathrm{~min}$ ). (a) the $0.15 \%$ La-added steel; (b) the $0.10 \%$ La-added steel; (c) the $0.05 \%$ La-added steel. (Online version in color.)

position of steel, mainly including arsenic, aluminum, and magnesium, while the composition changes of silicon and manganese caused by the evolution of inclusions were not significant because of their original high content. Figure 4 shows the changes in arsenic, lanthanum, magnesium, and acid-soluble aluminum content in the steel throughout the steelmaking process.

The results show that, for the $0.15 \%$ La-added steel, the arsenic content was significantly reduced after $5 \mathrm{~min}$ of adding lanthanum, while the content of magnesium and aluminum was significantly increased. It can be inferred that lanthanum reacted with arsenic and $\mathrm{La}-\mathrm{S}-\mathrm{As}$ inclusions formed, which floated to the surface of molten steel and caused a decrease in the arsenic content. ${ }^{26)}$ The increase in magnesium content was attributed to the reaction between lanthanum and the magnesia crucible since the latter was the only source of magnesium, and the increase in aluminum content is attributed to the reaction between lanthanum and the alumina that initially presented in the steel.

With the extension of the isothermal time until $20 \mathrm{~min}$ after the addition of lanthanum, the arsenic content gradually increased. We believe this is due to the steel-refractory reactions that significantly reduced the lanthanum content in the steel. This leads to the reverse of the reaction that generates La-S-As. Therefore, some As-containing inclusions decomposed and put arsenic back into molten steel.

Besides, the magnesium content increased first and then decreased. After the lanthanum-crucible reaction caused the increase in magnesium content, magnesium gradually reacted with $\mathrm{Si}-\mathrm{Mn}-\mathrm{Al}-\mathrm{O}$ inclusions that initially existed in the steel. The dissolved magnesium replaced the silicon, manganese, and aluminum in the inclusions, resulting in the subsequent reduction in the magnesium content.

Although more aluminum left in steel when using alumina crucibles than that of magnesium when using magnesia crucibles, we believe that the reaction of lanthanum with the magnesia crucible is more severe than of lanthanum with the alumina crucible. The former leads to more consumption of lanthanum and less effective lanthanum for the removal of arsenic. The produced magnesium possibly became magnesium vapor to escape from the molten steel due to its high saturation vapor pressure, which dramatically decreased the residual magnesium content. This explains why the magnesium content in both $0.15 \%$ and $0.10 \%$ La-added steels is similar. Moreover, it was difficult to separate the ingots from the magnesia crucible after the smelting had ended (Fig. 5), indicating severe reactions of lanthanum with the crucible. In contrast, the ingots and the alumina crucibles separated themselves caused by the shrinking of the ingots during the cooling process. ${ }^{26}$ )

For the $0.10 \%$ La-added steel, the addition of lanthanum only slightly reduced the arsenic content, and it returned to the initial concentration within 15 min after the addition of lanthanum. This means lanthanum mainly reacted with the magnesia crucible and sulfur but rarely with arsenic.

For the $0.05 \%$ La-added steel, the addition of lanthanum 

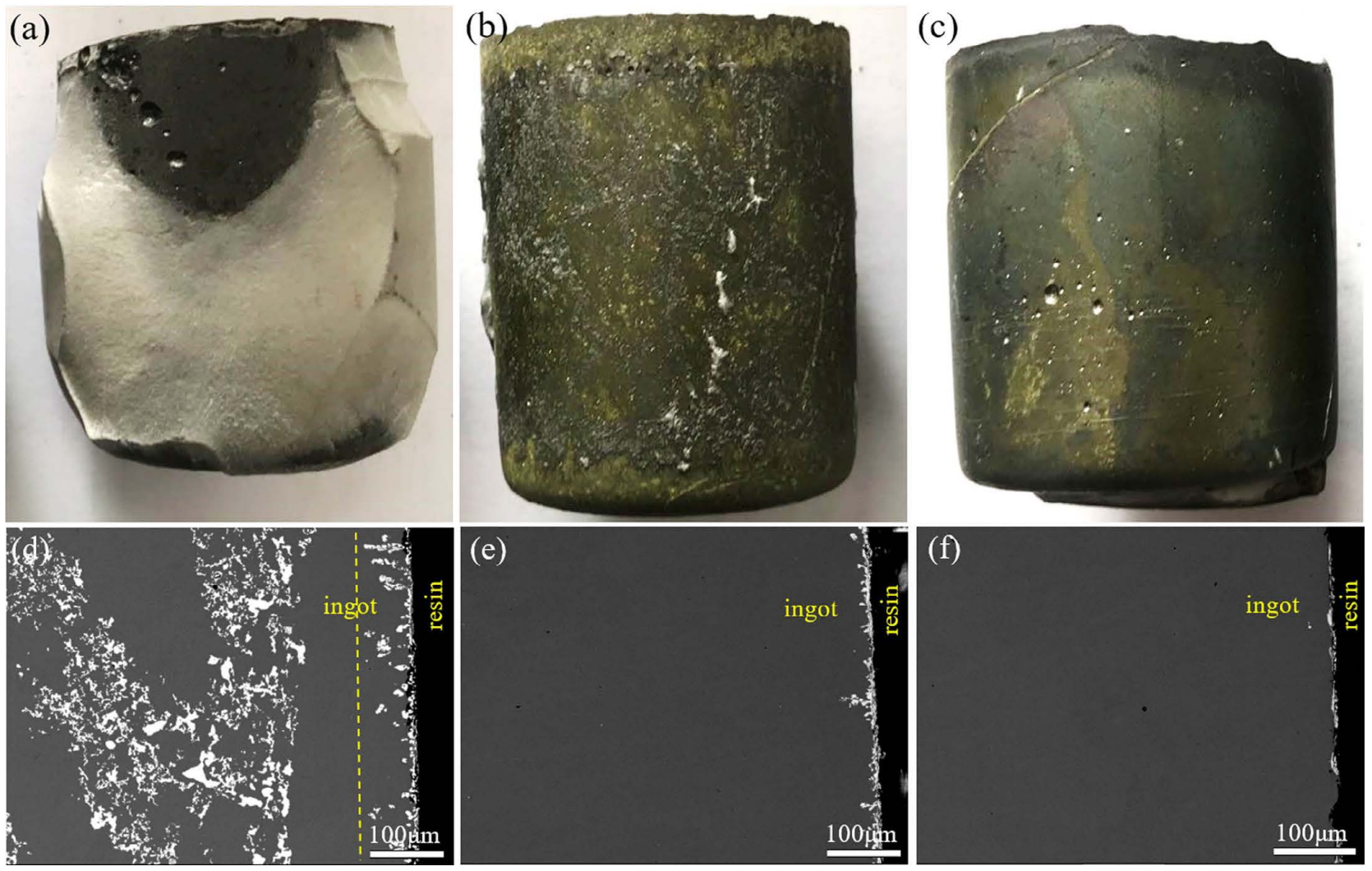

Fig. 5. Morphologies of the ingots and the interfaces with magnesia crucibles. (a) to (c) the ingots of $0.15 \%, 0.10 \%$, and $0.05 \%$ La-added steels; (d) to (f) the interfaces of magnesia crucibles with $0.15 \%, 0.10 \%$, and $0.05 \%$ La-added steel ingots. (Online version in color.)

also slightly reduced the arsenic content that returned to the initial concentration later. It is worth noting that the addition of $0.05 \%$ La had little effect on the content of aluminum and magnesium, because the dissolved magnesium replaced mainly $[\mathrm{Si}]$ and $[\mathrm{Mn}]$ in the $\mathrm{Si}-\mathrm{Mn}-\mathrm{Al}-\mathrm{O}$ inclusions, resulting in very low magnesium content.

\subsection{Inclusions Types and Distribution in the Ingots}

As stated in section 3.2, the amount of lanthanum determines the degree of the reaction between lanthanum and crucibles. Distribution of inclusions at the interface between the ingot and crucibles directly reflects the severity of these steel-refractory reactions, as shown in Fig. 5. It can be seen that the amounts of inclusions are different at the side surface of ingots. The thickness of these inclusion-containing layers is proportional to the amount of lanthanum added. The thickness is about $100 \mu \mathrm{m}$ for the $0.15 \%$ La-added steel ingot, to the right of the yellow dotted line, as shown in Fig. 5(d). Meanwhile, some cluster-shaped La-O-S-As inclusions with a thickness of about $0.5 \mathrm{~mm}$ were randomly discovered to the left of the yellow dotted line near the side surface.

Figure 6 shows the morphologies and compositions of inclusions at the side surface of the $0.15 \%$ La-added steel ingot. It shows that the inclusions on the right side of the yellow dotted line are mainly $\mathrm{La}_{2} \mathrm{O}_{3}$ and $\mathrm{La}_{2} \mathrm{O}_{2} \mathrm{~S}$, both of which can exist alone, and the former can serve as the heterogeneous nuclei of the latter (Figs. 6(a)-6(c)). To the left of the yellow dotted line, the inclusions are $\mathrm{LaS}, \mathrm{L}_{2} \mathrm{O}_{2} \mathrm{~S}$, and La-S-As. As shown in Fig. 6(d), large inclusions are LaS$\mathrm{L}_{2} \mathrm{O}_{2} \mathrm{~S}-(\mathrm{La}-\mathrm{S}-\mathrm{As})$ composite inclusions, and the small ones are mainly La-S-As. It can be inferred that the formation sequence of the $\mathrm{La}-\mathrm{O}-\mathrm{S}-\mathrm{As}$ inclusions is $\mathrm{La}_{2} \mathrm{O}_{3}, \mathrm{~L}_{2} \mathrm{O}_{2} \mathrm{~S}$, $\mathrm{LaS}$, and $\mathrm{La}-\mathrm{S}-\mathrm{As}$, in good accordance with the previous work. ${ }^{16)}$ For the $0.10 \%$ and $0.05 \%$ La-added steels, only $\mathrm{La}_{2} \mathrm{O}_{3}$ and $\mathrm{L}_{2} \mathrm{O}_{2} \mathrm{~S}$ turned out to be the dominant inclusions. All these inclusions are mainly generated at $1600^{\circ} \mathrm{C}$, except some inclusions at the interface of steel and crucible. They formed during the solidification and cooling process and could not move away.

Figure 7 shows the morphologies and compositions of inclusions at the top surface of the $0.15 \%$ La-added steel ingot. Except for the $\mathrm{La}-\mathrm{O}-\mathrm{S}-\mathrm{As}$ inclusions that were also discovered at the side surface of ingot, many $\mathrm{MgO}$ inclusions were found, as shown in Figs. 7(b)-7(c). We noted that few $\mathrm{MgO}$ inclusions stayed at the side surface of ingots. This proves that $\mathrm{MgO}$ formed in molten steel, and they quickly floated to the top surface owing to a small density of $3.59 \mathrm{~g} / \mathrm{cm}^{3}{ }^{27)} \mathrm{La}-\mathrm{S}-\mathrm{As}$ inclusions were also found on the top surface of ingot, as shown in Figs. 7(d)-7(e). Besides, La-O-S-As inclusions with finer size were also found inside the ingots, owing to the decreasing solubility of solutes lanthanum, oxygen, sulfur, and arsenic in the steel matrix during the cooling process. They have nothing to do with the removal of arsenic from steel, however.

\subsection{Evolution Mechanism of Inclusions and Effect of Steel-refractory Reactions on Arsenic Content}

As mentioned above, the addition of lanthanum considerably changed the type of inclusions and affected the residual arsenic content in the steel. Considering the evolution of inclusions, the composition changes of molten steel, and 


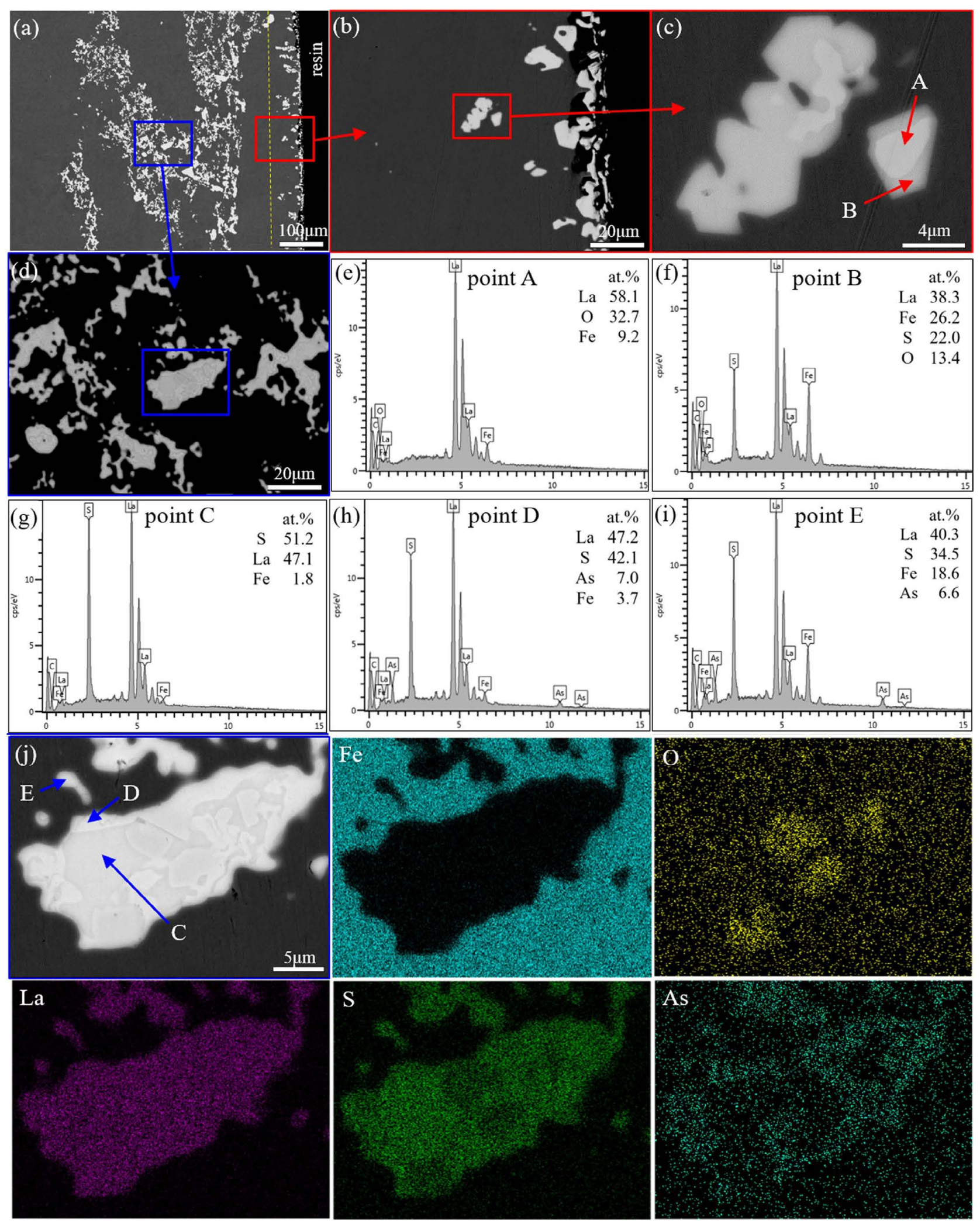

Fig. 6. Morphologies and compositions of inclusions at the interface of the $0.15 \%$ La-added steel ingot. (a) Morphologies of the interface at the side of ingot; (b) an enlarged map of the interface; (c) morphologies of $\mathrm{La}_{2} \mathrm{O}_{3}-\mathrm{La}_{2} \mathrm{O}_{2} \mathrm{~S}$ composite inclusions; (d) an enlarged map of La-O-S-As inclusions; (e) EDS of point A; (f) EDS of point B; (g) EDS of point C; (h) EDS of point D; (i) EDS of point E; (j) an enlarged map of $\mathrm{LaS}-\mathrm{La}_{2} \mathrm{O}_{2} \mathrm{~S}-(\mathrm{La}-\mathrm{S}-\mathrm{As})$ composite inclusions and single $\mathrm{La}-\mathrm{S}-\mathrm{As}$ inclusions. (Online version in color.)

the distribution of inclusions in ingots, we discussed the reactions related to lanthanum and arsenic in molten steel. Then, we use a figure to describe the evolution mechanism of inclusions and the influence of steel-refractory reactions on the residual arsenic content in steel, as shown in Fig. 8.
After the lanthanum was dissolved in molten steel, the thermodynamically possible reactions mainly involve lanthanum, aluminum, magnesium, oxygen, sulfur, and arsenic. It is believed that the kinetic conditions determine which reactions are dominant at a time since these reactions are 

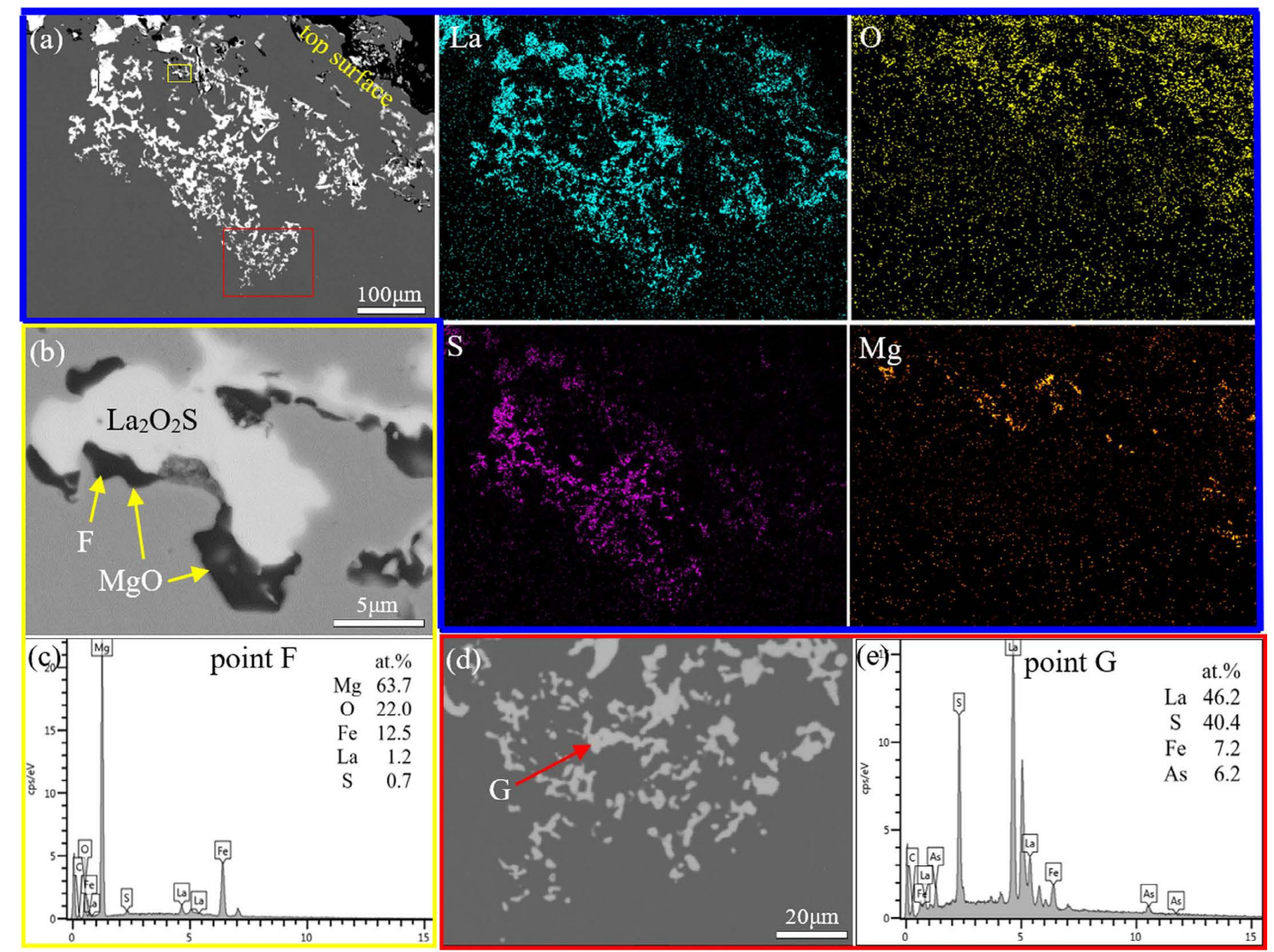

Fig. 7. Morphologies and compositions of inclusions at the top surface of the $0.15 \%$ La-added steel ingot. (a) Morphologies of the top surface; (b) an enlarged map of $\mathrm{La}_{2} \mathrm{O}_{2} \mathrm{~S}-\mathrm{MgO}$ composite inclusions; (c) EDS of point $\mathrm{F}$; (d) an enlarged map of mainly La-S-As inclusions; (e) EDS of point G. (Online version in color.)

adding As

adding $\mathrm{La}$

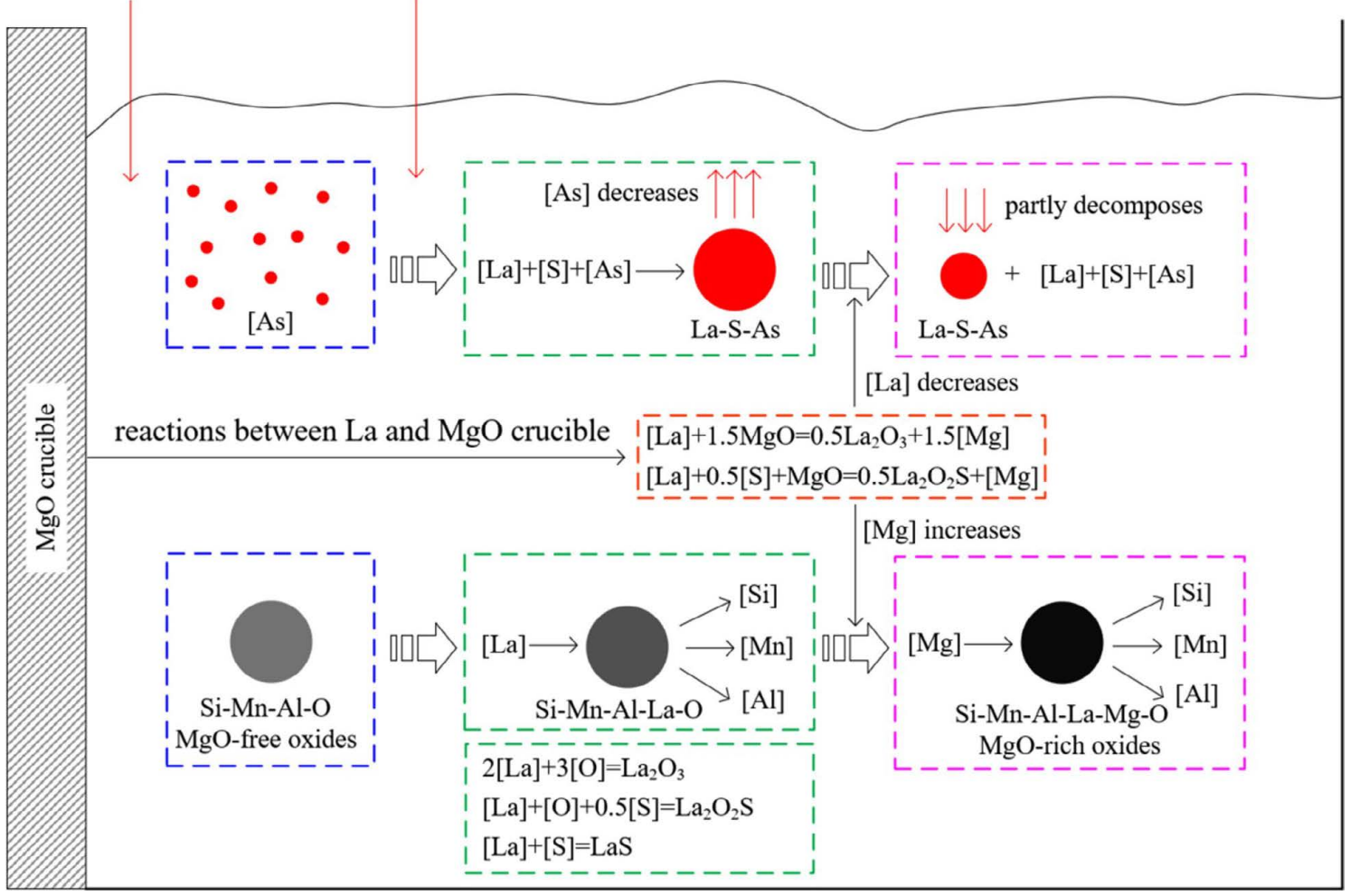

Fig. 8. Evolution mechanism of inclusions in molten steel. (Online version in color.) 
all thermodynamically possible. Two types of reactions involved here: liquid-liquid reactions and solid-liquid reactions. The first $\mathrm{RE}$ inclusion forms in steel is usually $\mathrm{RE}_{2} \mathrm{O}_{3}$ or $\mathrm{RE}_{2} \mathrm{O}_{2} \mathrm{~S}$ (Eqs. (1) and (2)), determined by the activities of [O] and [S], and RES follows (Eq. (4)). ${ }^{16,28,29)}$ Based on the same calculation method and interaction coefficients of components used in the previous work, ${ }^{16)}$ the activities of [La], [O], and [S] were calculated. It turns out that the activity ratio of $[\mathrm{O}]$ and $[\mathrm{S}]$ in Eq. (3) equals to 0.12 under equilibrium conditions, indicating that $\mathrm{La}_{2} \mathrm{O}_{3}$ forms first if the lanthanum content is higher than $0.025 \%$ based on the compositions of steel listed in Table 1. Therefore, the formation sequence is $\mathrm{La}_{2} \mathrm{O}_{3}, \mathrm{La}_{2} \mathrm{O}_{2} \mathrm{~S}$, and $\mathrm{LaS}$ after the addition of lanthanum in this work. Although the formation of La-S-As cannot be calculated owing to the lack of thermodynamic data (Eq. (5)), it is reasonable to consider that $\mathrm{La}-\mathrm{S}-\mathrm{As}$ forms after $\mathrm{LaS}$ because the latter severs the heterogeneous sites for the former as mentioned above. The formation of La-S-As dramatically reduced the arsenic content in molten steel. At the same time, the reactions between lanthanum and liquid $\mathrm{Si}-\mathrm{Mn}-\mathrm{Al}-\mathrm{O}$ inclusions also existed (Eq. (6)). All these inclusions floated up to the surface of molten steel due to the density difference between the inclusions and molten steel or were captured by the crucible wall.

$$
\begin{aligned}
& 2[\mathrm{La}]+3[\mathrm{O}]=\mathrm{La}_{2} \mathrm{O}_{3}(\mathrm{~s}) \\
& \Delta G^{\circ}=-1511520+379.2 T(\mathrm{~J} / \mathrm{mol}) \\
& 2[\mathrm{La}]+2[\mathrm{O}]+[\mathrm{S}]=\mathrm{La}_{2} \mathrm{O}_{2} \mathrm{~S}(\mathrm{~s}) \\
& \Delta G^{\circ}=-1425820+351.0 T(\mathrm{~J} / \mathrm{mol}) \\
& {[\mathrm{S}]+\mathrm{La}_{2} \mathrm{O}_{3}(\mathrm{~s})=\mathrm{La}_{2} \mathrm{O}_{2} \mathrm{~S}(\mathrm{~s})+[\mathrm{O}]} \\
& \Delta G^{\circ}=-R T \ln \left(\frac{a_{[\mathrm{O}]}}{a_{[\mathrm{S}]}}\right)=85700-28.2 T(\mathrm{~J} / \mathrm{mol}) \\
& {[\mathrm{La}]+[\mathrm{S}]=\mathrm{LaS}(\mathrm{s}) \quad \Delta G^{\circ}=-490000+171.0 T(\mathrm{~J} / \mathrm{mol}) \ldots} \\
& {[\mathrm{La}]+[\mathrm{S}]+[\mathrm{As}] \rightarrow \mathrm{La}-\mathrm{S}-\mathrm{As}(\mathrm{s})}
\end{aligned}
$$

$[\mathrm{La}]+\mathrm{Si}-\mathrm{Mn}-\mathrm{Al}-\mathrm{O}(\mathrm{l}) \rightarrow \mathrm{La}_{2} \mathrm{O}_{3}(\mathrm{~s})+[\mathrm{Si}, \mathrm{Mn}, \mathrm{Al}] \ldots(6)$

As the extension of constant temperature time, although the steel-refractory reactions are solid-liquid reactions with relatively poor reaction kinetics, they became dominant when dissolved oxygen and sulfur were consumed to a low content (Eq. (9)). ${ }^{30,31)}$ The dissolved magnesium reacted with the remaining $\mathrm{Si}-\mathrm{Mn}-\mathrm{Al}-\mathrm{O}$ inclusions, promoting the transformation of these inclusions to $\mathrm{MgO}$-rich ones (Eq. $(10)){ }^{32)}$

$$
\begin{aligned}
& 2[\mathrm{Al}]+3[\mathrm{O}]=\mathrm{Al}_{2} \mathrm{O}_{3}(\mathrm{~s}) \\
& \Delta G^{\circ}=-1225000+393.8 T(\mathrm{~J} / \mathrm{mol})
\end{aligned}
$$

$$
\begin{gathered}
{[\mathrm{Mg}]+[\mathrm{O}]=\mathrm{MgO}(\mathrm{s}) \quad \Delta G^{\circ}=-89980-81.9 T(\mathrm{~J} / \mathrm{mol}) \ldots} \\
2[\mathrm{La}]+3 \mathrm{MgO}(\mathrm{s})=\mathrm{La}_{2} \mathrm{O}_{3}(\mathrm{~s})+3[\mathrm{Mg}] \\
\Delta G^{\circ}=-1241580+624.9 T(\mathrm{~J} / \mathrm{mol}) \\
3[\mathrm{Mg}]+\mathrm{Al}_{2} \mathrm{O}_{3}(\mathrm{~s})=3 \mathrm{MgO}(\mathrm{s})+2[\mathrm{Al}] \\
\Delta G^{\circ}{ }_{1873 \mathrm{~K}}=-242724 \mathrm{~J} / \mathrm{mol}
\end{gathered}
$$

h

(1)

formation of As-containing inclusions. First, the continuous consumption of lanthanum sharply reduced the effective concentration of lanthanum for reacting with arsenic, which inhibited the reaction to generate $\mathrm{La}-\mathrm{S}-\mathrm{As}$ and promoted the reaction to proceed in the reverse direction. Second, the dissolved magnesium consumed a part of sulfur and reduced its effective concentration acting on the formation of $\mathrm{La}-\mathrm{S}-$ As, as shown by Eqs. (11)-(12). ${ }^{33,34)}$

$$
\begin{gathered}
{[\mathrm{Mg}]+[\mathrm{S}]=\operatorname{MgS}(\mathrm{s})} \\
\Delta G^{\circ}=-521470+183.1 T(\mathrm{~J} / \mathrm{mol}) \\
{[\mathrm{Mg}]+\mathrm{LaS}(\mathrm{s})=\mathrm{MgS}(\mathrm{s})+[\mathrm{La}]} \\
\Delta{G^{\circ}}_{1873 \mathrm{~K}}=-8807 \mathrm{~J} / \mathrm{mol}, \quad \Delta{G^{\circ}}_{1773 \mathrm{~K}}=-10017 \mathrm{~J} / \mathrm{mol}
\end{gathered}
$$

It is noted that, for the removal of arsenic from molten steel by adding REs, alumina crucibles are more favored over magnesia crucibles. On the one hand, the dissolved magnesium will consume a part of sulfur, which is disadvantageous to the generation of $\mathrm{La}-\mathrm{S}-\mathrm{As}$ (Eq. (12)). This is against the key theory of using REs to generate $\mathrm{La}-\mathrm{S}-\mathrm{As}$ inclusions to remove arsenic. This is to say, ternary compound $\mathrm{La}-\mathrm{S}-\mathrm{As}$ has a higher formation temperature than that of La-As binary compounds. It is reported that CeAs binary compounds started to precipitate during and after solidification; ${ }^{17)}$ therefore, they cannot be removed from steel. It is a similar situation for La-As binary compounds because of the similar shell electron structure of $\mathrm{La}$ and $\mathrm{Ce}$. If the sulfur concentration is too low, La-As binary or $\mathrm{LaAsO}_{4}$ ternary compounds will be generated instead of La-S-As. ${ }^{16)}$ On the other hand, kinetic conditions of the reactions between lanthanum and magnesia crucibles are more advantageous than that between lanthanum and alumina crucibles. The results prove that few $\mathrm{MgO}$ inclusions were found at the steel-crucible interfaces because all of them floated up to the surface of molten steel, which promoted the reactions between lanthanum and magnesia crucibles. When using alumina crucibles, however, many $\mathrm{LaAlO}_{3}$ inclusions were found at the steel-crucible interfaces, which inhibited the steel-crucible reactions.

Generally speaking, when smelting RE-containing steels, it is essential to set an appropriate constant temperature time in any case. Also, using slags to absorb RE-S-As inclusions benefits the removal of arsenic from molten steel. In this way, we can keep La-S-As inclusions from decomposing, thereby keeping arsenic from entering molten steel again.

\section{Conclusions}

The effect of lanthanum on the removal of arsenic from molten steel when the steelmaking process was carried out in magnesia crucibles was studied, and the influence of steel-refractory reactions on the evolution of inclusions has been discussed. The following conclusions were obtained.

The addition of lanthanum can be used to remove arsenic from molten steel, but the removal effect was dramatically influenced by the reactions between lanthanum and magnesia crucibles. The reaction product dissolved magnesium consumed a part of sulfur, resulting in a decrease in the effective concentration of sulfur. This is against the key theory for arsenic removal from molten steel by adding REs

The steel-refractory reactions significantly affected the 
to generate La-S-As. Alumina crucibles are more favored over magnesia crucibles for the removal of arsenic from molten steel.

A sequence of reactions existed after the addition of lanthanum. The addition of lanthanum changed the existing $\mathrm{Si}-\mathrm{Mn}-\mathrm{Al}-\mathrm{O}$ inclusions to La-containing oxides first, and then to $\mathrm{MgO}$-rich oxides. The generation of $\mathrm{La}-\mathrm{S}-\mathrm{As}$ mainly took place within 5 min after the addition of lanthanum. Therefore, it is necessary to choose an appropriate isothermal time after the addition of lanthanum to obtain a relatively high removal rate of arsenic.

\section{Acknowledgments}

This research was funded by the National Natural Science Foundation of China, grant number 51704051, Foundation of Key Laboratory for Ecological Metallurgy of Multimetallic Mineral (Ministry of Education), grant number NEMM2018001, and Chongqing Postdoctoral Funds, grant number Xm2017192. Many thanks to Mr. Chao Deng, from Electron Microscopy Center of Chongqing University, for his great help in the observation with SEM.

\section{REFERENCES}

1) R. Schweinfest, A. T. Paxton and M. W. Finnis: Nature, 432 (2004), 1008 .

2) A. Ohmori, A. Matsuzaki and K. Amano: ISIJ Int., 37 (1997), 302.

3) W. Xin, B. Song, C. Huang, M. Song and G. Song: Int. J. Miner. Metall. Mater., 22 (2015), 704

4) N. Bailey: Weldability of Ferritic Steels, Woodhead Publishing Ltd. in association with The Welding Institute, Cambridge, (1994), 212.

5) C. Nagasaki and J. Kihara: ISIJ Int., 37 (1997), 523.

6) H. Matsuoka, K. Osawa, M. Ono and M. Ohmura: ISIJ Int., 37 (1997), 255.

7) N. Imai, N. Komatsubara and K. Kunishige: ISIJ Int., 37 (1997), 217.

8) Z. Yu and C. Liu: Metals, 9 (2019), 804

9) W. Xin, J. Zhang, Y. Jiang, Y. Deng, Q. Meng and B. Song: Metall.
Res. Technol., 116 (2019), 415.

10) Y. Li, M. Sun, Z. Jiang, C. Chen, K. Chen, X. Huang, S. Sun and H. Li: Metals, 9 (2019), 54.

11) W. Xin, J. Zhang, G. Luo, R. Wang, Q. Meng and B. Song: Metall. Res. Technol., 115 (2018), 419.

12) H. Torkamani, S. Raygan, C. G. Mateo, J. Rassizadehghani, J. Vivas, Y. Palizdar and D. San-Martin: Metals, 7 (2017), 377.

13) J. Wang, L. Chang and L. Zhou: Adv. Mater. Res., 476-478 (2012), 273.

14) L. Luo, J. Wang, L. Wang and Z. Li: 6th Int. Symp. on HighTemperature Metallurgical Processing, Springer, Cham, (2015), 699.

15) H. Wang, B. Bai, S. Jiang, L. Sun and Y. Wang: ISIJ Int., 59 (2019), 1259.

16) H. Wang, L. Xiong, L. Zhang, Y. Wang, Y. Shu and Y. Zhou: Metall. Mater. Trans. B, 48 (2017), 2849.

17) W. Xin, B. Song, M. Song and G. Song: Steel Res. Int., 86 (2015), 1430.

18) W. G. Wilson, D. A. R. Kay and A. Vahed: JOM, 26 (1974), 14

19) A. Katsumata and H. Todoroki: Iron steelmak., 29 (2002), 51.

20) Y. Li, T. Zhang, C. Liu and M. Jiang: Metals, 9 (2019), 433.

21) S. K. Kwon, J. S. Park and J. H. Park: ISIJ Int., 55 (2015), 2589

22) S. K. Kwon, Y. M. Kong and J. H. Park: Met. Mater. Int., 20 (2014), 959.

23) H. Wang, S. Jiang, P. Yu, B. Bai, L. Sun and Y. Wang: Metals, 10 (2020), 146.

24) N. Kojola, S. Ekerot, M. Andersson and P. G. Jonsson: Ironmaking Steelmaking, 38 (2011), 1.

25) Z. Yu, W. Zhao, Y. Xie and Q. Yu: Iron Steel, 19 (1984), 18 (in Chinese).

26) H. Wang, P. Yu, S. Jiang, B. Bai, L. Sun and Y. Wang: Metals, 10 (2020), 275.

27) P. Villars, ed.: PAULING FILE in: Inorganic Solid Phases, Springer Materials (online database), Springer, Heidelberg, (2016).

28) P. E. Waudby: Int. Met. Rev., 23 (1978), 74.

29) X. Li, Z. Jiang, X. Geng, M. Chen and L. Peng: ISIJ Int., 59 (2019), 1552 .

30) H. Itoh, M. Hino and S. Ban-Ya: Tetsu-to-Hagané, 83 (1997), 623 (in Japanese).

31) D. S. Petrovič, B. Arh, F. Tehovnik and M. Pirnat: ISIJ Int., 51 (2011), 2069.

32) T. S. Zhang, Y. Min and M. F. Jiang: Can. Metall. Q., 54 (2015), 161.

33) J. Yang, K. Okumura, M. Kuwabara and M. Sano: ISIJ Int., 42 (2002), 685

34) Z. Wu, J. Li, C. Shi and L. Wang: Int. J. Miner. Metall. Mater., 21 (2014), 1062. 